3 Wilhelmus KR, Hynduik RA, Caldwell DR, Abshire RL, Folkens AJ, Godio LB, for Ciprofloxacin Ointment/Bacterial Study Group. 0.3\% ciprofloxacin ointment in the treatment of bacterial keratitis. Arch Ophthalmol 1993;111:1210-18

4 Madhavan HN, Rao SK, Joseph PR, Sulochana KN. Antibacterial activity of the white precipitate formed on the corneal surface after treatment with ciprofloxacin ophthalmic solution. Cornea 1999; 18:549-52

5 John T. Scanning electron microscopic study of a Ciloxan bottle blocked by ciprofloxacin crystals. Eye 2001;15:786-8

6 Kaufman HE, Barron BA, McDonald MB, Kaufman SC. Companion Handbook to the Cornea, 2nd edn. London: Butterworth-Heinemann, 2000:243-4

\section{Tortuous common carotid artery as a cause of dysphagia}

\author{
Ashish Gupta MRCS Marc C Winslet MS FRCS
}

J R Soc Med 2005;98:275-276

Dysphagia lusoria can be caused by any type of vascular ring ${ }^{1}$ but is commonly associated with an aberrant left or right subclavian artery, a right aortic arch or a common carotid artery aneurysm. ${ }^{2}$

\section{CASE HISTORY}

A woman of 82 was seen in outpatients after eight weeks of mild postcibal epigastric discomfort. She also gave a long history of dysphagia. 18 years previously, dilatation of an oesophageal stricture had been unsuccessful and the dysphagia had continued - only to solids, with occasional episodes of food bolus obstruction and difficulty in swallowing certain tablets. There had been no weight loss or change in appetite.

Her medical history included polymyalgia rheumatica, for which she was on steroids, and hypertrophic cardiomyopathy. She had smoked till the age of 40. On examination there was no pulsatile mass in the neck and the carotid pulsations on both sides were normal. A barium swallow showed a tight stricture of the lower cervical oesophagus with dilatation of the pharynx and the upper cervical oesophagus proximal to the stricture. The stomach and the duodenum were normal. The stricture had a smooth margin consistent with an extrinsic compression (Figure 1). MRI of the neck showed a tortuous right common carotid artery indenting the oesophagus (Figures 2 and 3). Upper gastrointestinal endoscopy was not performed because of the patient's poor cardiac status.

University Department of Surgery, Royal Free Hospital, Hampstead, London NW3 2QG, UK

Correspondence to: Professor Marc C Winslet

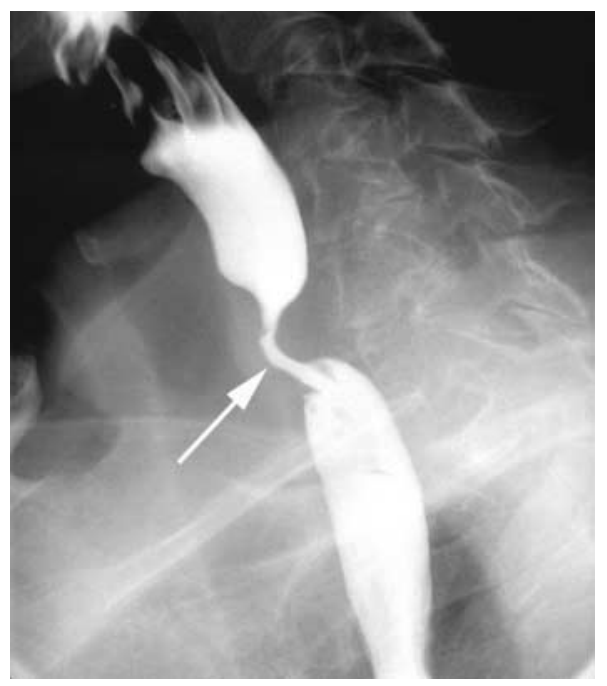

Figure 1 Barium swallow showing tight stricture of cervical oesophagus with proximal dilatation

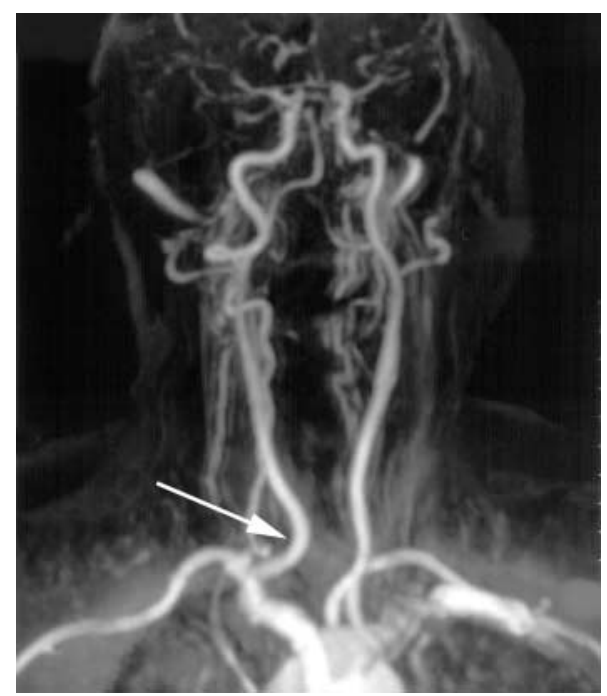

Figure 2 MR angiogram showing tortuous right common carotid artery

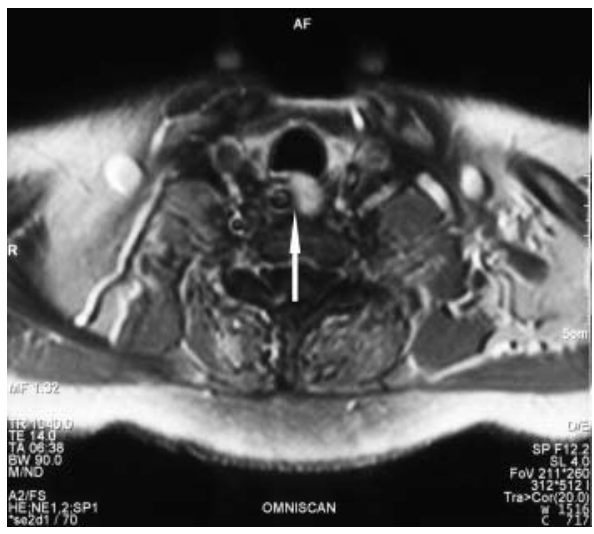

Figure 3 Axial MRI showing right common carotid artery displacing oesophagus to left 


\section{COMMENT}

Dysphagia from carotid artery kinks and coils seems very rare. In reported cases the internal carotid artery has usually been responsible. We have found only one case due to common carotid artery tortuosity - in which the redundant part of the artery was surgically resected and the dysphagic symptoms resolved completely. ${ }^{4}$ Elongation and kinking of the carotid artery are usually due to atherosclerosis or fibromuscular dysplasia, ${ }^{5}$ but the unusual location of the proximal common carotid artery coil in this patient is most likely congenital rather than atherosclerotic.

In a fitter patient the treatment of choice would have been a carotid shortening procedure. Dilatation by balloon or stent might provide palliation at the risk of cerebrovascular catastrophe and is contraindicated unless the vessel is known to be occluded.

\section{REFERENCES}

1 Morris CD, Kanter KR, Miller JI. Late-onset dysphagia lusoria. Ann Thorac Surg 2001;71:710-12

2 Furukawa H, Tsuchiya K, Osawa H, Saito H, Iida Y. Saccular descending thoracic aortic aneurysm with dysphagia. Jpn $J$ Thorac Cardiovasc Surg 1999;47:277-80

3 Takano S, Miyajima K, Sugiura E, Aramaki H. Two cases of tortuous internal carotid artery. Practica Oto-Rhino-Laryngologica 2003;96:559-62

4 Lin PH, Bush RL, Reddy P, Lumsden AB. An unusual cause of dysphagia. Coil of the proximal common carotid artery: a case report. Vasc Surg 2000;34:521-6

5 Schenk P, Temmel A, Tratting S, Kainberger F. Current aspects in diagnosis and therapy of carotid artery kinking. HNO 1996;44:178-85

\section{Spontaneous unilateral tubal twin pregnancy}

\section{S D Sur BChir(Cantab) MA K Reddy MRCOG FRCS}

J R Soc Med 2005;98:276

In a stable patient with tubal pregnancy, treatment with methotrexate often allows preservation of the tube. In spontaneous tubal twin pregnancy, of which only five cases have been reported, experiences with this method are lacking.

\section{CASE HISTORY}

A nulliparous woman of 24 attended the emergency department after a day of abdominal pain and brown

John Radcliffe Hospital, Oxford, UK

Correspondence to: S D Sur, 11 Bexley Court, Reading RG30 2DY, UK vaginal discharge. Her last menstrual period had been six weeks previously and a pregnancy test was positive. 4 years earlier she had been treated for chlamydia infection. On examination she was tender in the left iliac fossa without peritonism. Vaginal examination revealed cervical excitation and left adnexal tenderness. A left-sided ectopic pregnancy was suspected. Human chorionic gonadotropin (HCG) was $10500 \mathrm{IU} / \mathrm{L}$. Transvaginal sonography showed the uterus to be empty, with endometrium thickened at $15 \mathrm{~mm}$. The right ovary was normal with no adnexal masses. The left adnexa had two separate gestation sacs, each containing a fetal pole and yolk sac. Both fetal poles showed heart pulsation. The left ovary was normal. There was little fluid in the pouch of Douglas. Live left tubal twin pregnancy was diagnosed. At laparoscopy two separate bulges were seen on the left tube, and a salpingectomy was performed.

\section{COMMENT}

Sensitive methods for pregnancy diagnosis together with high-resolution transvaginal sonography mean that ectopic pregnancy can often be diagnosed at an early stable stage, allowing medical management in selected cases. The Royal College of Obstetricians and Gynaecologists ('Green Top Guidelines') recommends discussion of methotrexate with the patient if serum HCG is $<3000 \mathrm{IU} / \mathrm{L}$, the tubal mass is moderate in size, there is no heartbeat and the pouch of Douglas contains no free fluid. ${ }^{1}$ A single dose of methotrexate $50 \mathrm{mg} / \mathrm{m}^{2}$ then offers $85 \%$ success in resolution of the pregnancy with a $7 \%$ risk of tubal rupture. Our patient did not satisfy these criteria in various ways, including the high $\mathrm{HCG}$.

In a retrospective study Lipscombe et al. ${ }^{2}$ reported mean HCG of $4019 \mathrm{IU} / \mathrm{L}$ in 350 women successfully treated with methotrexate compared with 13420 in 30 women unsuccessfully treated. Stika et al. ${ }^{3}$ reported that single-dose methotrexate was universally unsuccessful when serum HCG exceeded 5000. A high serum HCG level is also associated with increased risk of tubal rupture. ${ }^{4}$

\section{REFERENCES}

1 Royal College of Obstetricians and Gynaecologists. The Management of Tubal Pregnancy, Guideline No. 21. London: RCOG, 2004

2 Lipscombe GH, McCord ML, Stovall TG, Huff G, Portera SG, Ling FW. Predictors of success of methotrexate treatment in women with tubal ectopic pregnancies. N Engl J Med 1999;341:1974-8

3 Stika CS, Anderson L, Fredriksen MC. Single dose methotrexate for the treatment of ectopic pregnancy: Northwestern Memorial Hospital three year experience. Am J Obstet Gynecol 1996;174:1840-8

4 JobSpira N, Fernandez H, Bouyer J, Pouly JL, Germaine E, Coste J. Ruptured tubal ectopic pregnancy: risk factors and reproductive outcome - results of a population based study in France. Am J Obstet Gynecol 1999; 180:938-44 